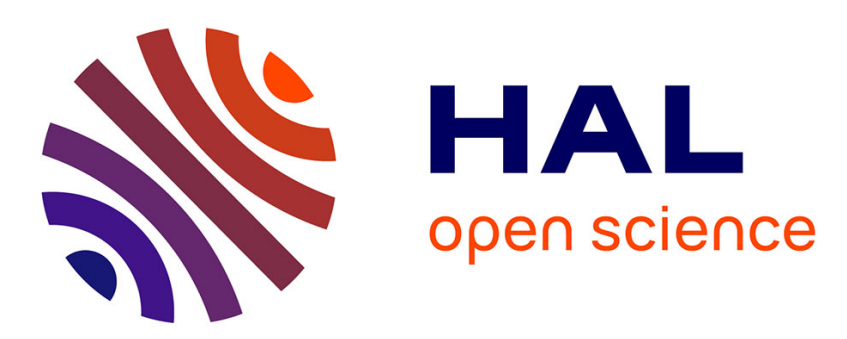

\title{
Scanning calorimeter for microliter-scaled samples based on lithium tantalite pyroelectric bulk material
}

S. Youssef, J. Podlecki, R. Habchi, M. Brouche, R. Al Asmar, A. Foucaran

\section{To cite this version:}

S. Youssef, J. Podlecki, R. Habchi, M. Brouche, R. Al Asmar, et al.. Scanning calorimeter for microliter-scaled samples based on lithium tantalite pyroelectric bulk material. European Physical Journal: Applied Physics, 2011, 56 (1), pp.11201. 10.1051/epjap/2011110075 . hal-00736282

\section{HAL Id: hal-00736282 \\ https://hal.science/hal-00736282}

Submitted on 28 Sep 2012

HAL is a multi-disciplinary open access archive for the deposit and dissemination of scientific research documents, whether they are published or not. The documents may come from teaching and research institutions in France or abroad, or from public or private research centers.
L'archive ouverte pluridisciplinaire HAL, est destinée au dépôt et à la diffusion de documents scientifiques de niveau recherche, publiés ou non, émanant des établissements d'enseignement et de recherche français ou étrangers, des laboratoires publics ou privés. 


\title{
Scanning calorimeter for microliter-scaled samples based on lithium tantalite pyroelectric bulk material
}

Sami Youssef ${ }^{\mathrm{a}, \mathrm{b}, \mathrm{c}^{*}}$, Jean Podlecki ${ }^{\mathrm{a}}$, Roland Habchi ${ }^{\mathrm{b}}$, Marwan Brouche ${ }^{\mathrm{c}}$, Roy Al Asmar ${ }^{\mathrm{b}}$, Alain Foucaran $^{\mathrm{a}}$

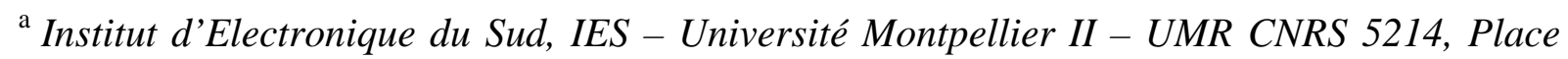
Eugène Bataillon, 34095 Montpellier - France.

${ }^{\mathrm{b}}$ Laboratoire de Physique Appliquée (LPA), Département de Physique, Université libanaise, Faculté des sciences II, 90656 Jdeidet - Liban.

c Ecole supérieure d'ingénieurs de Beyrouth, Campus des Sciences et Technologies, Mar Roukoz, B.P. 1514, Riad El Solh, Beyrouth 11072050 - Liban.

E-mail : sami.youssef@ies.univ-montp2.fr

\begin{abstract}
We report the design and operation of a differential scanning calorimeter (DSC) for use with either solid or liquid samples with a volume down to a few microliters. The calorimeter is based on lithium tantalite pyroelectric bulk material used to perceive the energy involved in any phase transformation process. The device consists of a pyroelectric substrate, a thermoelectric cooler and a heat dissipation system. Its effectiveness is demonstrated by scanning the freezing and melting phase shifts of water droplets, ranging from 1 to $2 \mu \mathrm{l}$. The latent heat of fusion and solidification were measured to within $3 \%$ of the bulk value.
\end{abstract}




\section{Introduction}

Calorimetry is a very useful technique for studying the thermodynamic properties of materials. Unfortunately the conventional differential scanning calorimeter (DSC) is limited to macroscopic samples $[1,2]$ but calorimetry has the potential to investigate materials on a very small scale [3]. Much progress has been made in the development of calorimeters for the analysis of ultrathin films, these calorimeters have been used to study liquid-solid and liquidvapor transformations at small scales [4], glass transition in ultrathin polymer films [5], biological macromolecules, basic biological processes of individual cells [6], and phase transformation [7]. A lot of micro-electromechanical DSCs have been developed for energetic studies or for heat-capacity measurements [4] but none of them is reported to be based on pyroelectric materials such as $\mathrm{LiTaO}_{3}$ or $\mathrm{LiNbO}_{3}$. The major advantage of this configuration is that it uses a pyroelectric material that could replace platinum based DSCs as previously reported in [8] for a better detection of very small variations of energy. The detected pyroelectric current is in fact proportional to the gradient of temperature.

In this study a $\mathrm{LiTaO}_{3}$ based DSC is introduced to help measuring and quantifying the solidification and the melting phenomena of micro-liter samples subjected to a temperature gradient. The pyroelectric crystal, lithium tantalite $\mathrm{LiTaO}_{3}$, is used to make a new measuring system coupled to aluminum electrodes which will be used as a sample holder and a reference. The temperature gradient is provided by a Peltier module.

\section{Experimental procedure}

The measuring configuration is formed by a pyroelectric material, $\mathrm{LiTaO}_{3}$ plate $(1 \mathrm{~cm} \times 1 \mathrm{~cm} \times 300 \mu \mathrm{m})$, glued to a copper plate by a thermal paste. A negative temperature coefficient NTC thermistor is introduced into the copper plate and the system is placed on the cool side of a Peltier module. The heat is evacuated from the hot side through a heat sink as shown in figure 1. The temperature is regulated by a programmable temperature controller. The $\mathrm{LiTaO}_{3}$ is sandwiched between two couples of electrodes formed by $3 \mathrm{~mm}$ radius, $200 \mathrm{~nm}$ thick aluminum discs, deposited by magnetron sputtering. Electrodes couples are placed in a head-to-tail configuration in order to make a differential current measurement, thus the output current will be insignificant if the discs undergo the same temperature gradient. One of the upper aluminum discs will serve as a reference and the other will be used to hold the water droplet to be analyzed. The output current runs through a transimpedance amplifier to 
facilitate the measurement as shown in figure 2. Thought that humidity is an important factor in this type of studies, the system was used only when the humidity was under $30 \%$.

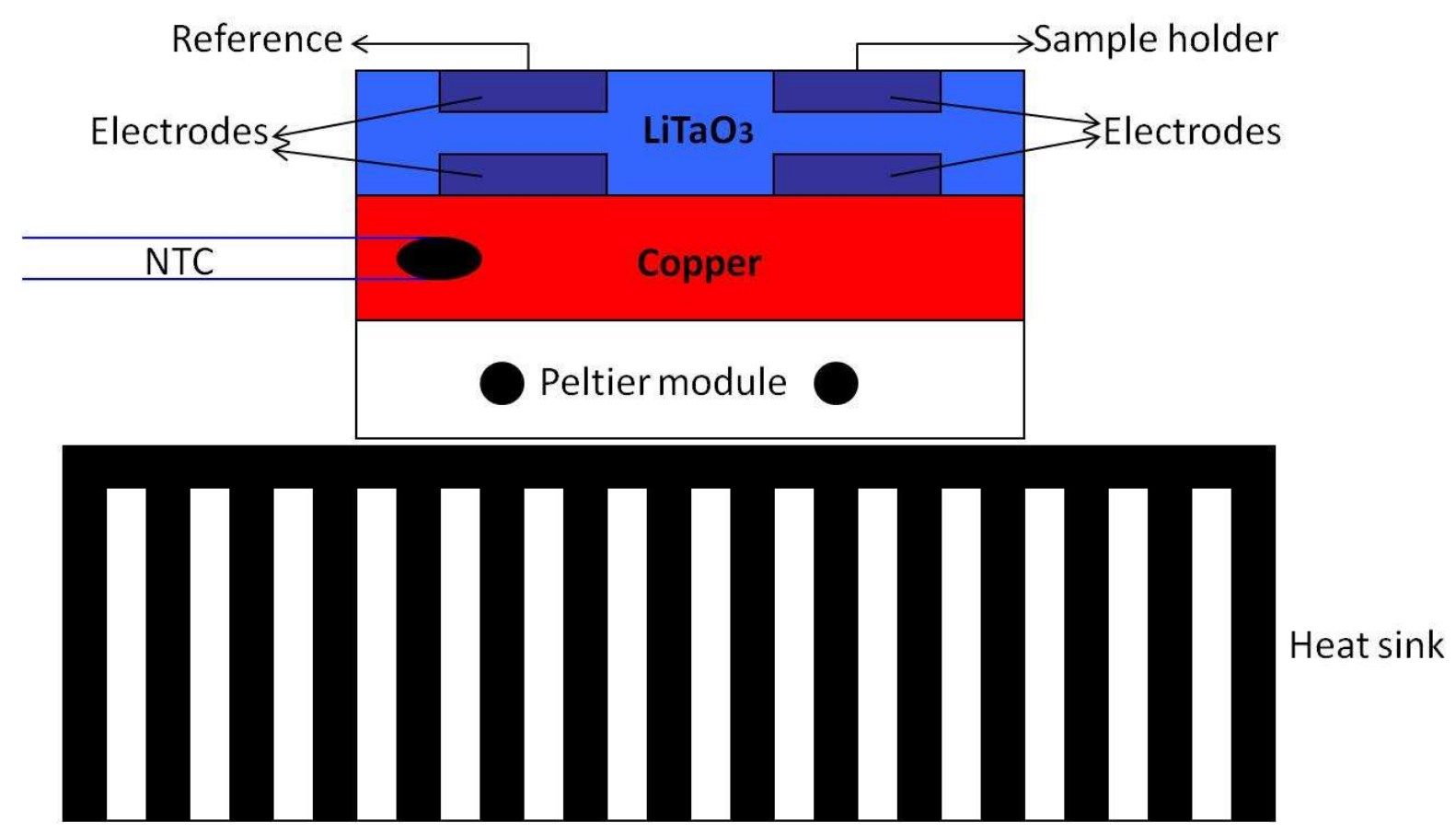

Figure 1. Cross section of the measuring system. The $\mathrm{LiTaO}_{3}$ plate is $1 \mathrm{~cm} \times 1 \mathrm{~cm}$ x $300 \mu \mathrm{m}$.

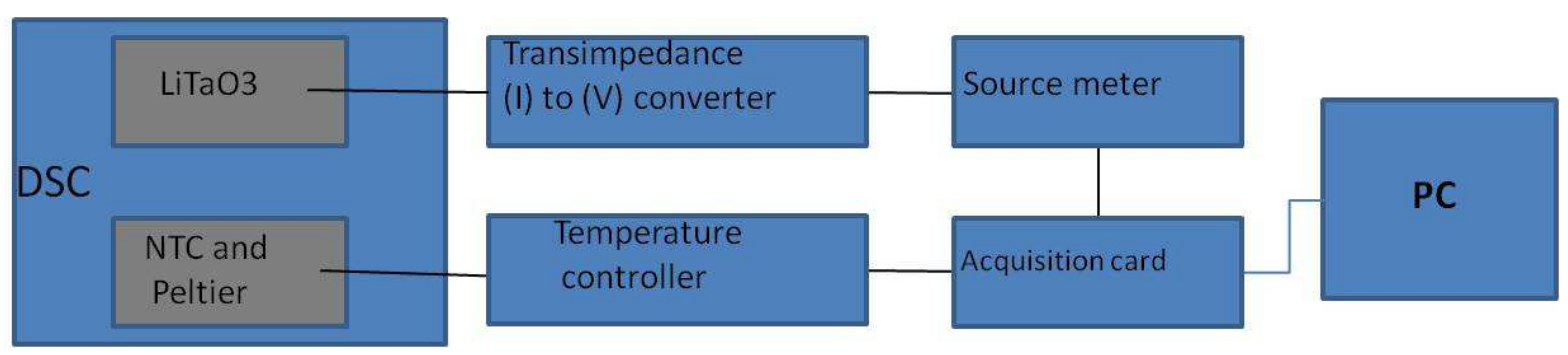

Figure 2. The measuring configuration used to collect data.

\section{Results and discussion}

A $1.5 \mu 1$ water droplet was placed over one of the electrodes, the system was cooled down to $-15^{\circ} \mathrm{C}$ and then heated up to $10^{\circ} \mathrm{C}$ in order to identify the solidification and fusion phase of the water droplet. The temperature value is collected from the NTC thermistor, but it does not reflect the real temperature of water considering the systems' configuration of figure 1 . Ultimately it's the closest we can get considering the difficulty of placing a probe on a micro- 
liter droplet. The measured differential voltage is shown in figure 3, a first peak is observed when the temperature reaches $-12^{\circ} \mathrm{C}$, before reaching the minimal value of $-15^{\circ} \mathrm{C}$, marking the beginning of water solidification, and a second peak marks the end of solidification. When the water is entirely frozen, the differential voltage returns to zero. The distance between the two peaks gives the time taken by the droplet to be completely solidified which in this case is equal to 4 seconds. When the system is heated, the water begins to liquefy and the variation of the differential current (converted to differential voltage by the transimpedance) shows an opposite behavior to the one observed in solidification. The reason is that when the water is freezing it releases energy, while it absorbs energy when melting so the pyroelectric material undergoes a positive then a negative temperature gradient explaining why the generated currents have opposite signs.

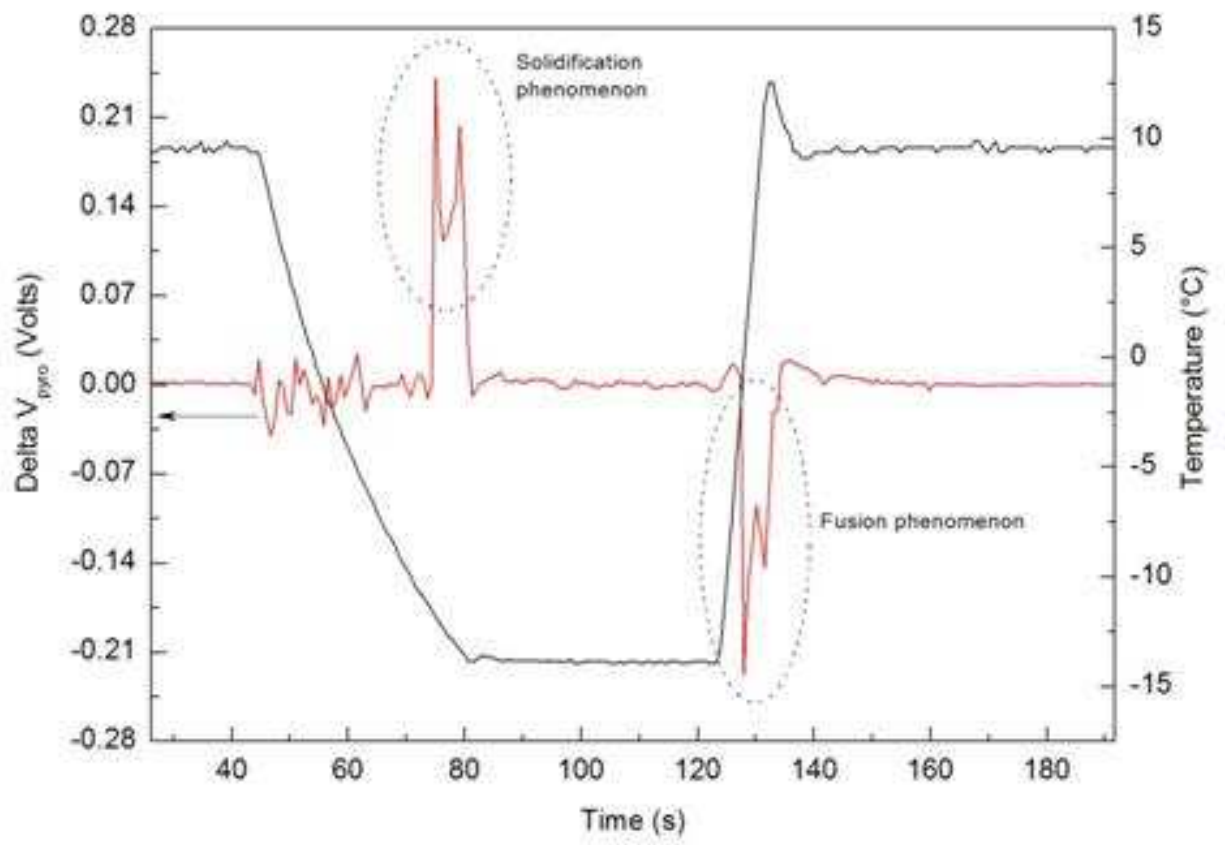

Figure 3. The voltage variation as collected from the pyroelectric material, and the temperature variation of the Peltier module.

The pyroelectric current is proportional to the derivative of temperature with respect to time, so the temperature variation underwent by the pyroelectric material could be calculated through the integral of the temperature derivative. Results are shown in figure 4. 


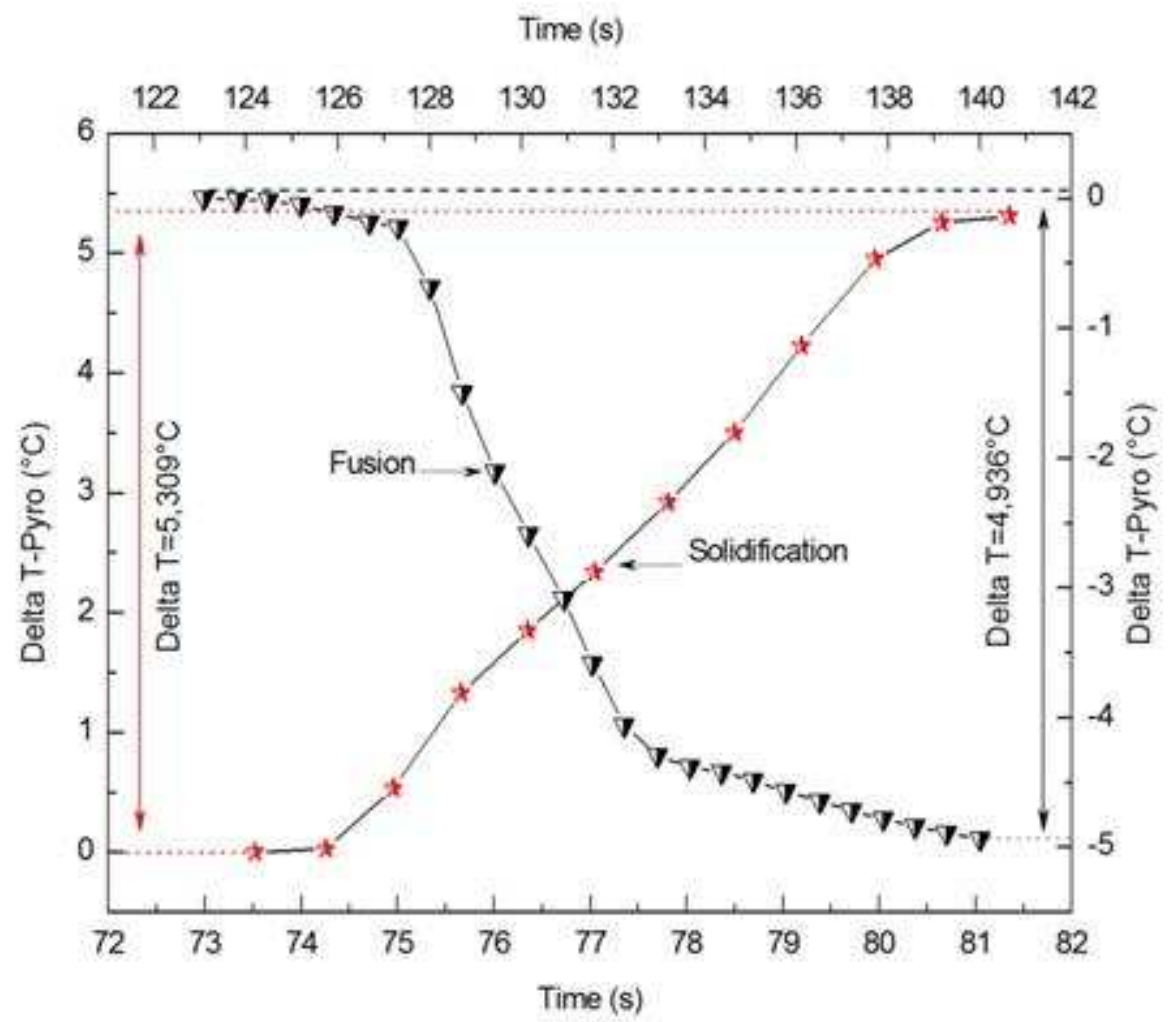

Figure 4. Temperature variation of the bulk $\mathrm{LiTaO}_{3}$ during solidification and fusion phenomena.

In this figure the temperature variation of $\mathrm{LiTaO}_{3}$ is scanned at $-15^{\circ} \mathrm{C}$ and $10^{\circ} \mathrm{C}$ respectively, during solidification the temperature change is positive which means that the temperature of $\mathrm{LiTaO}_{3}$ is increased when the water shifts from liquid to solid. In opposition, the temperature of $\mathrm{LiTaO}_{3}$ decreases throughout the melting phenomenon due to heat absorption during the phase change. The amount of energy released or absorbed during this change of state is determined by:

$E=m \times C_{p} \times \Delta T$

Where $\mathrm{m}$ is the mass of the $\mathrm{LiTaO}_{3}$ substrate $(0.2235 \mathrm{~g})$, and $\mathrm{C}_{\mathrm{p}}$ is the heat capacity equal to $3.2 \mathrm{~J} / \mathrm{cm}^{3} . \mathrm{K}, \Delta \mathrm{T}$ is temperature variation. The values of the released and absorbed heat are $0.509 \mathrm{~J}$ and $0.473 \mathrm{~J}$ corresponding to the cooling and heating temperatures of $-15^{\circ} \mathrm{C}$ and $10^{\circ} \mathrm{C}$ respectively. Considering the mass of $\mathrm{LiTaO}_{3}$ the latent heat of solidification $\mathrm{L}_{\mathrm{s}}$ is then -339.3 $\mathrm{J} / \mathrm{g}$ and the latent heat of fusion is $315.3 \mathrm{~J} / \mathrm{g}$. Compared to the bulk value of latent heat of solidification of water at atmospheric pressure $(-333 \mathrm{~J} / \mathrm{g})$, our value is very close and the relative error is less than $3 \%$. 
As noticed previously, the relative humidity should be low. If the humidity is high, above $35 \%$, water droplet will form on the surface of the device leading to an unstable response of the pyroelectric sensor, and then the generated current will increase indefinitely even if the temperature is stable.

\section{Conclusion}

A new application related to pyroelectric materials has been demonstrated. The prototype presented allows the study of liquid or solid samples with a volume down to a few microliters. This calorimeter is able to measure the latent heat of transformations, and its use has been demonstrated with the solidification and the melting of water droplets. Ultimately, the $\mathrm{LiTaO}_{3}$ will be deposited as a thin film [9] on platinum resistors to form a sensor in which the metal layer will be only used as a resistive heater and the pyroelectric $\mathrm{LiTaO}_{3}$ for the detection.

\section{Acknowledgements}

The authors gratefully acknowledge Jean-Michel Gosalbes for his technical assistance.

\section{References}

[1] M. J. M. Van Oort and M. A. White, Rev. Sci. Instrum. 58, 1239 (1987)

[2] V. K. Pecharsky, J. O. Moorman, and K. A. Gschneidner, Jr., Rev. Sci. Instrum. 68, 4196 (1997)

[3] E. A. Olson, M. Yu. Efremov, A. T. Kwan, S. Lai, V. Petrova, F. Schiettekatte, J. T. Warren, M. Zhang, L. H. Allenb. Scanning calorimeter for nanoliter-scale liquid samples, Applied Physics Letters 772671 (2000)

[4] E. A. Olson, M. Y. Efremov, M. Zhang, Z. Zhang, L. H. Allen. The design and operation of a MEMS differential scanning nanocalorimeter for high-speed heat capacity measurements of ultrathin films. J. Microelectromech. S. 12355 (2003)

[5] M. Yu. Efremov, J. T. Warren, E. A. Olson, M. Zhang, A. T. Kwan, L. H. Allen. Thinfilm differential scanning calorimetry: A new probe for assignment of the glass transition of ultrathin polymer films. Macromolecules 351481 (2002)

[6] JM Sturtevant. Biochemical Applications of Differential Scanning Calorimetry. Annual Review of Physical Chemistry 384633 (1987)

[7] A.F. Lopeandia, L.1. Cerdo, M.T. Clavaguera-Mora, L.R. Arana, K.F. Jensen, F.J. Munoz, J. Rodriguez-Viejo. Sensitive power compensated scanning calorimeter for analysis of phase transformations in small samples. Rev. Sci. Instr. 76065104 (2005)

[8] S. Youssef. MEMS scanning calorimeter with serpentine-shaped platinum resistors for characterizations of microsamples. J. Microelectromech. S. 18414 (2009)

[9] S. Youssef, R. Al Asmar, J. Podlecki, B. Sorli, A. Foucaran. Structural and optical characterization of oriented $\mathrm{LiTaO}_{3}$ thin films deposited by sol-gel technique. Eur. Phys. J. Appl. Phys. 4365 (2008) 